\title{
The Development of Higher Education Quality Based on The Accreditation of Study Program
}

\author{
Abdurahman Adisaputera (Author) \\ Indonesia Language Faculty \\ State University of Medan \\ Medan, Indonesia \\ abas_750@yahoo.co.id
}

\author{
Isda Pramuniati (Author) \\ Indonesia Language Faculty \\ State University of Medan \\ Medan, Indonesia \\ pramuniatiisda@gmail.com
}

\begin{abstract}
The public trust and recognition on accreditation is so high that the recognition of the quality of higher education is determined by its accreditation status and rank. In order to realize the transparent public accountability, higher educations must actively build an internal quality assurance system and can prove that the internal quality assurance system has implemented well and correctly. The general purpose of this research is to find the development design of higher education quality based on The National Accreditation Board of University (BAN PT) accreditation standard before and after accreditation and prove the influence of accreditation for the development of study program at higher education. The method used to achieve the objectives of the research is through mixing methods of qualitative and quantitative. The research results show there is a significant correlation of the understanding to the Unimed policy with understanding the study program on accreditation form on standard items: human resources and financing, facilities and infrastructure, as well as information systems. while on standards vision, mission, objectives and goals, as well as achievement strategies, governance, leadership, management system, and quality assurance, students and graduates, and research, service/community service, and cooperation there is no significant correlation and so with the understanding of the study program toward the Unimed policy with accreditation value obtained from BAN-PT.
\end{abstract}

Keywords - accreditation; higher education; quality; study program

\section{INTRODUCTION}

According to Law No. 12 of 2012 on higher education, it is stated that higher education is the level of education after secondary education, one of which covers undergraduate, master, profession and diploma programs held by universities based on Indonesian culture. Medan State University (Unimed) as an educational provider has a strategic role in educating the nation and promoting science and technology by taking into account and applying the humanities value as well as the sustainable culture and empowerment of the Indonesian nation.

The National Accreditation Board of University (BAN- PT) is the only Accreditation Board recognized by the government of Indonesia to implement accreditation in higher education. The main function of BAN PT according to existing legislation
(Law No. 20 of 2003); reaffirmed on the Law no 12 of 2012 on university or college, article 55 paragraphs 4.5 and 6 which states accreditation of universities undertaken by the National Accreditation Board. The strength of BAN-PT's role is supported by a system that lacks recognition of unaccredited higher education degrees. Article 28, Verse 3, Law No. 12 of 2012 even confirms the academic degree and vocational title are declared invalid and revoked by the minister if issued by the higher education and or Study Program that is not accredited.

There are two preliminary studies as well as the results of research relevant to the proposed proposal: Research conducted by Mahriyuni (2015), under the title "Development of Mentoring Model to improve school accreditation" concludes that in improving the quality of academic services, national education as stipulated in the accreditation standard. Institutions need to set standards that are equal to or exceed national education standards.

The research conducted by Sugiyono et al (2012) with the title of study "study of performance evaluation of PGSD Study Program Post Accreditation" concluded that the accreditation assessment result is used to improve the relevance and efficiency of the Study Program. Efforts made to achieve the value of high accreditation, among others through the optimization of internal quality assurance system Study Program. Therefore, it is necessary to develop a model of university planning based on projections, predictions and estimates, both on physical planning and program. Physical planning through the development of campus land to the fulfillment of facilities and laboratory equipment [1]

In order to realize transparent public accountability, Unimed must actively build an internal quality assurance system to prove that the internal quality assurance system has been properly and properly implemented. Universities must be accredited by an external quality assurance institution. With a good quality assurance system, universities will be able to improve quality, uphold autonomy, and develop themselves as academic institutions and moral strength of society in a sustainable manner. 
As a qualified university, it is demanded for tridarma activities that must be implemented that is teaching activities, research and community service. In the implementation of tridarma, Unimed is expected to be able to produce scientific work of research results and community service according to the Unimed vision achievement "Becoming a Superior University in Education, Industrial Engineering and Culture". The scope of the research as well as the theme of leading research in RIP and Research Renstra 2012-2016 about research clumps in education, industrial engineering and culture. In addition, one of the institutional policy strategies under the RPJMN 2015-2019 in Unimed Renstra 2016-2020 is through the strategy of "Improving the accreditation quality of Institutional and Study Program" with the key performance indicators on the target number of study programs which are accredited A, AIPT Rating, the number of accredited Study Program OEDC (cumulative). The outcomes of the activities of the entire Unimed Study Program earned accreditation rating A so as to apply for OEDC International accreditation in accordance with the achievement of 13 Unimed breakthroughs to prepare the superior and competitive human resources, as well as the potential and strategic role of Unimed to "World class University" (WCU). This is stated in the Long-Term of 2011-2025. Development of Unimed.

Unimed quality control and quality assurance is essential to improve the competitiveness of Regional (Subject to RIP Unimed). Some of the guidelines used as quality standards, among others, are measured from the ratio between the students and the lecturers, the management, the adequacy of facilities, the graduate competence, the graduate application, the cooperation of study program, and the scientific work, and the information system in teaching. All these standards are contained in accreditation standards that are evaluated comprehensively on the commitment of the Study Program to conduct quality study programs.

The Kemenristekdikti currently has launched an accreditation program for institutions that have the potential to raise the accreditation rating of institutions from $B$ to $A$ as many as 35 higher education institutions throughout Indonesia. Unimed is included in the Institution accreditation grant because it previously received a score of 353 B Rankings in 2014. At this time the preparation of Institution Accreditation forms (AIPT) found obstacles unmet data, including the number of the student body in Unimed, graduates, study period and student's GPA Study Program D3, S1, S2 and S3) are not synchronized between BAAK, Puskom, PDPT Dikti, Unimed mission vision statement that has not been synergized with the vision of the mission of the higher education so the echo of mission and vision has not wrapped up for all academic activities and scientific products produced by lecturers. The activities of lecturers and students in academic interaction, scientific publications, have not obtained the optimal results. This has an impact on institutional targets in raising the Unimed Accreditation rating.

The meaning of accreditation in the book "Standar dan Prosedur Akreditasi Program studi Sarjana state that accreditation is one of the evaluation quality and feasibility of higher education or study program conducted by organization or independent body outside the college. [3] Decisions regarding the quality are based on an assessment of the evidence relating to established standards and judgments of informed experts. The accreditation result is an acknowledgment that an institution or course has met the established quality standard, so it is feasible to carry out its programs.

In the explanation, it contained the meaning of the importance of accreditation for the study program. Accreditation refers to the process of evaluating courses that give official degrees (undergraduate, master and doctorate), in order to meet predetermined criteria and standards for each type of degree. "The things that are evaluated at the time of accreditation include: self-assessment, external assessment, draft of accreditation report and final report The evaluation result of the study program has an impact on the acceptance or cancellation of the study program If the study program is not accredited, the study program does not get quality recognition from the public and the government so that the study program loses the right to award the title.

The Accreditation concept in universities is used to guarantee and develop the quality of the institution or part of the institution that is the study program. The objectives and benefits of the study program accreditation according to BANPT are as follows: 1) Providing assurance that the accredited study program meets the quality standard stipulated by BAN$\mathrm{PT}$, so $\mathrm{t}$ hat it provides protection for the community from the implementation of study program that does not meet standard. 2) Encouraging the study programs/ higher education to continuously improve and maintain high quality 3) Accreditation results can be used as consideration in credit transfers, proposals for assistance and allocation of funds, and received recognition from agencies or agencies concerned. [2]

From some of the above understanding, accreditation of universities has an important role as the quality control of education. Without an accreditation agency, a university will likely grow like a course institution that does not have clear standards of quality. With the accreditation, the organization of university is more orderly and the quality is guaranteed because there are several accreditation standards that must be met. If the college does not have an accreditation status then the unaccredited college graduate certificate is not recognized and cannot be used as a requirement to occupy a position in the formal employment sector.

The quality of the undergraduate course is the totality of the circumstances and characteristics of the undergraduate input, process and product or service course as measured by a number of standards as a benchmark for assessment to determine and reflect the quality of a higher education institution. In other words, accreditation standards are the benchmarks that must be met by undergraduate courses. One accreditation standard consists of several parameters (assessment elements) that can be used as a basis for measuring and establishing the quality and eligibility of the undergraduate course to carry out its programs.

Each country has an assessment standard of the quality of study programs at different universities. BAN-PT uses 7 (seven) undergraduate study accreditation standards consisting of two standards on the commitment of undergraduate courses 
to institutional capacity and five standards that support the commitment to educational effectiveness. The standards used for accreditation of undergraduate courses in Indonesia are:

a) Standard 1. Vision, Mission, Objectives and Goals, as well as Achievement Strategies

b) Standard 2. Governance, Leadership, Management System, and Quality Assurance

c) Standard 3. Students and Graduates

d) Standard 4. Human resources

e) Standards 5. Curriculum, Learning, and Academic Atmosphere

f) Standard 6. Financing, Facilities and Infrastructure, as well as Information Systems

g) Standard 7. Research, Service/Community Service, and Cooperation.

States that the quality assurance is required by universities so that they are able to: (1) Competing to be in globalization where the competition among educational institutions will increase, (2) Meeting the customers' satisfaction, now customers demand good quality in teaching and acquire a number of skills to work. (3) Maintaining the standards so that the higher education always strive to improve the quality of education process in accordance with predetermined standards. (4) Maintaining accountability, quality will ensure that something is done accountable and can provide information to stakeholders to take the right decision. (5) Improving the morale and motivation of the employees. The quality of the institution will increase the spirit and motivation of the employees in carrying out their duties and responsibilities. (6) Credibility, prestige and status. The quality will be performed on behalf of individuals and institutions will bring the credibility of the status and name of the concerned university or college. (7) Image and visibility, the quality of institutions has the capacity to attract the stakeholder support, to increase much easier the number of contributions and graduate placements. [4]

To find out whether the accreditation standards in Indonesia are still relevant to measure the quality of current study programs, the following are reviewed some of the accreditation standards used in Europe, America and Asia. The quality assurance of education in Europe is conducted by three quality assurance institutions: internal quality assurance, external quality assurance of HEI (Higher Education Institution), quality assurance of external quality assurance agencies. "Standards and Guidelines for Quality Assurance which are used by educational institutions in the European proposed by the European Network for Quality Assurance in Higher Education (ENQA) in 2001. [5]

\section{RESEARCH METHODS}

The method used to achieve the objectives of the research is through mixing methods of qualitative and quantitative, evaluation method or evaluative study with qualitative approach through case study and explorative. Quantitative methods used to find out the tendency data both projection and prediction data in accordance with the type and diversity of data. The development of spatial design is conducted through an integrated approach between the approach of centralized regional growth with decentralization approach that emphasizes on the dissemination and participatory. Therefore, the data collection instruments consist of form fields, quality checklists, observation sheets, interview guides and documentation.

This study is also a study of management policy of higher education quality on the research umbrella/field of effective management, with the aim of developing the quality development of Unimed based on accreditation standards. To achieve the purpose of this study evaluation method or evaluative study are used with qualitative approach through case study and explorative.

In an effort to collect the research data in accordance with the needs, carried out four stages of policy research referring to the steps compiled namely: (1) Formulating the problem; (2) Planning research; (3) Conducting research; and (4) Presenting research findings and communicating recommendations. [6]

The stages in this policy research are as follows: (1) Preparing the research design in the form of research proposal. (2) Submitting a research proposal to Dikti through Lemlit of Unimed. (3) Preparing letters to meet the requirements for conducting research visits. (4) Finding an overview of the research flow. (5) Preparing the need, research equipment for the smooth collection of research data. (6) Coordinating and discussing with relevant stakeholders. (7) Collecting necessary data and information. (8) Consolidating and triangulating for the completeness and correctness of the data. (9) Routinely keeping a daily log of data collected (logbook). (B) identification of higher education standards, (c) studying of quality development based on accreditation of Study Program, (d) studying of data and information on implementation of Unimed development policy in accordance with research focus covering (a) Existing resources and potential of Unimed, analysis of the needs of accreditation standards, (e) preparing the recommendations on the revision of Unimed development strategic plan, and (f) preparing the research publication articles in accredited national journals. (11) creating a report of research activities

\section{RESEARCH RESULT AND DISCUSSION}

The achievement of accreditation of study program at Medan State University until now has made significant progress. Almost all study programs have been accredited B. In fact, there are many who get the accreditation of A. Here is presented the accreditation scores of study pro rams in Unimed. The data in the Table 1 above shows that since 2014 Unimed already has 24 study programs to get $B$ for accreditation value and 24 study programs obtain A for accreditation value.

Understanding of study program on the development policy on the study program at State University of Medan can be proved through the correlation level between the understandings of study program to the Unimed policy with the understanding of the study program on the form of Study program accreditation. Through this research, it is reviewed 
based on each accreditation standard in the accreditation form of BAN-PT.

The correlation of the understanding of the study program to the Unimed policy in developing the study program with the understanding of the study program to the item statement in the standard 1 of accreditation form shows that the value of correlation coefficient is -0.062 . This value indicates there is no significant relationship between the two. And so the correlation coefficient which shows there is no significant relationship from the understanding of the study program on Unimed policy with the achievement of accreditation value from BAN PT on standard one.

TABLE. 1 Understanding of Study Program for first Standard Form

\begin{tabular}{|l|l|c|c|}
\hline & & PBS1 & BANPT1-1 \\
\hline PKS1 & $\begin{array}{l}\text { Pearson } \\
\text { Correlation }\end{array}$ & -0.062 & -0.06 \\
\cline { 2 - 4 } & Sig. (2-tailed) & 0.673 & 0.687 \\
\cline { 2 - 4 } & N & 48 & 48 \\
\hline
\end{tabular}

The study program can obtain a high score of governance performance if the program implements the governance and the leadership that takes into account the five principles of credible, accountable, objective, transparent and fair. The program management systems use well-documented operational standards and procedures (SOPs). The understanding of the study program on planning and implementation of the governance system, leadership, management system, and quality assurance at the university and in the study program can be shown in table 3 below.

TABLE. 2 Understanding of Study Program for Second Standard Form

\begin{tabular}{|c|c|c|c|}
\hline & & PBS2 & BANPT 1-2 \\
\hline \multirow{3}{*}{ PKS2 } & $\begin{array}{c}\text { Pearson } \\
\text { Correlation }\end{array}$ & 0.011 & 0.175 \\
\cline { 2 - 4 } & Sig. (2-tailed) & 0.941 & 0.233 \\
\cline { 2 - 4 } & $\mathrm{N}$ & 48 & 48 \\
\hline
\end{tabular}

The data above shows the correlation level of the understanding of study program of Unimed policy in developing podi on the standard 2 of accreditation form which is at significance level of 0.011 . This value indicates that there is no significant correlation between the two. And so the understanding of development policies by Unimed with the accreditation value on the standard 2 of BAN-PT which show that there is no significant relationship on both variables which indicated a significance value of 0.175 .

The performance of the study program is determined by the quantity and quality of the students. Some indicators used to measure the quality include: (1) the ratio of prospective students who participated in the selection of capacity; (2) the ratio of new regular students who register for new prospective freshmen who pass the selection. The indicators show the poor quality of the students include: (1) the ratio of new transferred students to new regular students; (2) The non-regular students enrollment (should not make the lecturer's load very heavy, far exceeding the ideal load of about 12 credits); (3) the students who DO (drop out) or resign. The indicators that indicate the quality of good graduates include: Percentage of timely graduation with a satisfactory average grade point average (GPA). Understanding of study program to the students and the graduates of study program can be shown in table 4 below.

TABLE. 3 Understanding of Study Program for Second Standard Form

\begin{tabular}{|c|c|c|c|}
\hline & & PBS3 & BANPT 1-3 \\
\hline PKS3 & $\begin{array}{c}\text { Pearson } \\
\text { Correlation }\end{array}$ & 0.799 & 0.855 \\
\hline & Sig. (2-tailed) & 0.03 & 0.031 \\
\hline & $\mathrm{N}$ & 48 & 48 \\
\hline
\end{tabular}

The data above shows the correlation level of the understanding of the study program of Unimed policy in developing study program on the standard 3 of accreditation form which is at significance level of 0.03 . This value indicates a significant relationship/correlation on both. Likewise with the understanding of development policies by Unimed with the value of accreditation on the standard 3 of BAN-PT which shows a significant relationship of both these variables which indicated a significance value of 0.031 .

Human resources is the motor of performance wheel of study program. Without reliable human resources, activities of study program can be paralyzed or cannot run smoothly. The quality of human resources is determined by the acceptance system which has no nepotism element, the lecturer's performance is continuously evaluated, the S2/S3 education qualification is in accordance with the competence of the PS, the number of lecturers with the head lecturer upwards, and the number of lecturers has the Professional Educator Certificate. The quantity indicator is measured from the ratio of the students to the permanent lecturers whose skills are in accordance with the field of PS, the average lecturer's load per semester, or the average FTE (Fulltime Teaching Equivalent), the attendance of the lecturer in teaching, and the ratio of the number of lecturers, of the total number of lecturers. The understanding of the study program of human resources in the study program can be seen in table 5 below.

TABLE 4 Understanding of Study Program for Fourth Standard Form

\begin{tabular}{|c|c|c|c|}
\hline & & PBS4 & BANPT 1-4 \\
\hline PKS4 & Pearson Correlation & -0.038 & 0.124 \\
\hline & Sig. (2-tailed) & 0.796 & 0.401 \\
\hline & $\mathrm{N}$ & 48 & 48 \\
\hline
\end{tabular}

The data above shows the level of correlation of the understanding of the study program of Unimed policy in developing study program on the standard 4 of accreditation form is at significance level of 0.769 . This value indicates that there is no significant correlation between the two. Likewise 
with the understanding of development policies by Unimed with the value of accreditation on the standard 3 of BAN-PT which shows a significant relationship of both these variables which indicated a significance value of 0.031 .

To be able to get high accreditation value on the curriculum standard, learning, and academic atmosphere, hence there are some support program activities to get high scores. The key indicator of this standard lies in the quality assurance system of the learning process. To ensure the learning process is well organized and in accordance with the standard, the study program needs to conduct curriculum review activities, curriculum adjustment with the development of science and technology, quality control in the planning, implementation and evaluation of learning. In addition to the learning process, another thing that is assessed in the accreditation is the academic atmosphere. The correlation between understanding of study program in standard 5 and the achievement of accreditation value on standard 6 can be seen in the following table.

TABLE 5 Understanding of Study Program for Fifth Standard Form

\begin{tabular}{|c|c|c|c|}
\hline PKS5 & PBS5 & BANPT 1-5 \\
& $\begin{array}{c}\text { Pearson } \\
\text { Correlation }\end{array}$ & 0.058 & 0.178 \\
\hline & Sig. (2-tailed) & 0.696 & 0.227 \\
\hline & $\mathrm{N}$ & 48 & 48 \\
\hline
\end{tabular}

The correlation of understanding of the study program to the Unimed policy in developing with the understanding of the study program on the statement item in the standard 5 of the accreditation form shows the correlation coefficient value of 0.696. This value indicates that there is no significant relationship between the two. And so the correlation coefficient which shows there is no significant relationship from the understanding of the study program on the Unimed policy with the achievement of accreditation value from BAN PT for the 5 standard.

The means of infrastructure that meets the standards are measured from the area of the lecturer's workspace, the infrastructure (office, classroom, laboratory room, studio, library room, experimental garden, etc. except for the lecturers room) used by PS in learning process and other supporting infrastructure. The library standard is measured by the number of textbooks, dissertations/thesis//final project, accredited scientific journals of Dikti, international scientific journal, seminar proceedings, access to libraries outside PT and information systems facilities that support the access to other library resources. The understanding of the study program on financing, facilities and infrastructure, and information systems contained in boring accreditation point 3 available in the study program can be seen in table 7 below.
TABLE 6 Understanding of Study Program for sixth Standard Form

\begin{tabular}{|c|c|c|c|}
\hline PKS5 & $\begin{array}{c}\text { Pearson } \\
\text { Correlation }\end{array}$ & 0.058 & BANPT 1-5 \\
\hline & Sig. (2-tailed) & 0.696 & 0.178 \\
\hline & $\mathrm{N}$ & 48 & 0.227 \\
\hline
\end{tabular}

The data above shows the correlation level of the understanding of the study program on the Unimed policy in developing study program on standard 6 of accreditation form which is at significance level 0.088. This value indicates a significant relationship/correlation on both. And so the understanding of the study program on the development policy of Unimed with the accreditation value on the 6 standard of BAN-PT which shows a significant relationship of both variables which indicated a significance value of 0.035 .

The performance of the study program of the research elements and community service is measured by the quantity and quality of the research, scientific articles, Intellectual Property Rights (IPH) and the involvement of students in these activities over the past three years. The cooperation standards are assessed from cooperative activities with domestic and foreign agencies in the last three years. The lecturers are productive, many producing research work and dedication to the community strongly supports the PS achieve high marks on this standard. The understanding of the study program, research/service to the community, and cooperation contained in the accreditation form of point 3 available in the study program can be seen in table 8 below.

TABLE 7. Understanding of Study Program for Seventh Standard Form

\begin{tabular}{|c|c|c|c|}
\hline & & PBS7 & BANPT 1-7 \\
\hline PKS7 & Pearson Correlation & 0.036 & 0.159 \\
\hline & Sig. (2-tailed) & 0.81 & 0.28 \\
\hline & N & 48 & 48 \\
\hline
\end{tabular}

The data above shows the level of correlation of the understanding of study program of Unimed policy in developing study program on the standard 7 of accreditation form is at a significance level of 0.81 . This value indicates there is no significant correlation between the two. And so the understanding of development policy by Unimed with the value of accreditation on the standard 3 of BAN-PT which shows a significant relationship of the two variables that indicated a significance value of 0.28 .

\section{CONCLUSION}

The results of this study conclude that:

1) After mapping the accreditation scores of the study program in Unimed from 2014 until 2017, it is known that there are 48 study programs that have been accredited. 24 study programs have a value of accreditation $\mathrm{A}$, and 24 other study programs have accreditation value $\mathrm{B}$, 
2) There is a significant correlation of the understanding of the study program of the Unimed policy with the understanding of the study program on accreditation in point 4 and 6 standard. While in the standard 1,2,3, and 7 there is no significant correlation.

3) There is a significant correlation on the understanding of the study program to the Unimed policy with the accreditation value obtained from BAN-PT in point 4 and 6 standards. While the standard 1,2,3 and 7 there is no significant correlation..

\section{REFERENCES}

[1] Sugiyono, dkk (2012). Studi Evaluasi Performance Program Studi PGSD Pascaakreditasi. Laporan Penelitian. Jakarta: Badan Akreditasi Perguruan Tinggi.

[2] BAN-PT. (2008). Pedoman Evaluasi-diri Program Studi. Jakarta: Direktorat Jenderal Perguruan Tinggi.

[3] Rektor Unimed, 2010. Renstra Universitas Negeri Medan 2016-2020. Medan: Unimed Press.

[4] National Assessment and Accreditation Council. (2006). Quality Assurance in Higher Education di India. Banglore, India collaboration with Commonwealth with learning, Canada.

[5] Gaspersz , Vincent, 2001. "Penerapan Total Quality Management in Education (TQME) pada Perguruan Tinggi di Indonesia". dalam :'Jurnal Pendidikan dan Kebudayaan”. No. 029, Tahun Ke-7, Edisi Mei 2001, Balitbang Depdiknas Jakarta.

[6] Berg, Bruce L., 2001. Qualitative Research Methods for the Social Sciences, Fourth Edition, Boston: Allyn and Bacon.

[7] Unimed, 2011. Rencana Induk Penenlitian (RIP) Universitas Negeri Medan 2012-2016. Medan: Unimed Press. 